\title{
Capacidade de autodepuração em ambiente lótico a partir do modelo matemático de Streeter-Phelps no nordeste paraense
}

\author{
Self-depuration capacity in a lotic environment based on the mathematical model of Streeter- \\ Phelps in northeastern Para
}

Capacidad de autodepuración en un ambiente lótico basado en el modelo matemático de StreeterPhelps en el noreste de Pará

\author{
Antonio Pereira Junior \\ ORCID: https://orcid.org/0000-0001-6241-985X \\ Universidade do Estado do Pará, Brasil \\ E-mail: antonio.junior@uepa.br \\ Ayla Fernanda Muniz Miranda \\ ORCID: https://orcid.org/0000-0002-6702-0140 \\ Universidade do Estado do Pará, Brasil \\ E-mail: ayla_nanda_14@hotmail.com \\ Estefani Danielle de Araújo Barros \\ ORCID: https://orcid.org/0000-0003-1984-1937 \\ Universidade do Estado do Pará, Brasil \\ E-mail: barrosestefani@gmail.com \\ Aline Souza Sardinha \\ ORCID: https://orcid.org/0000-0001-6245-0734 \\ Universidade do Estado do Pará, Brasil \\ E-mail alinesardinha2uepa.br
}

\begin{abstract}
Resumo
$\mathrm{O}$ município de Capanema - PA, se desenvolveu às margens do rio Ouricuri. Em face disso, é importante o conhecimento da capacidade de autodepuração desse recurso hídrico. O objetivo desta pesquisa foi analisar quantiqualitativamente, a simulação da capacidade de autodepuração desse ambiente lótico, e propor duas medidas mitigatórias para a redução dos impactos gerados no corpo hídrico e melhorias na qualidade da água. O método foi dedutivo, abrangência quantiqualitativa e natureza aplicada. Os dados obtidos e analisados, para os três pontos, P1, P2 e P3, no período chuvoso: para o Rio Ouricuri foram, OD: $\bar{x}=0,26 \mathrm{mg} / \mathrm{L}$; DBO $5: \bar{x}=10 \mathrm{mg} / \mathrm{L} ;$ vazão: $\bar{x}=1,80 \mathrm{~m} 3 / \mathrm{s}$; temperatura: $\bar{x}=26{ }^{\circ} \mathrm{C}$, para a anilha de efluentes: OD: $\bar{x}=0,16 \mathrm{mg} / \mathrm{L}, \mathrm{DBO}_{5}: \bar{x}=300 \mathrm{mg} / \mathrm{L} ; \mathrm{vazão:} 0,88 \mathrm{~m} 3 / \mathrm{s}$; temperatura: $\bar{x}=26^{\circ} \mathrm{C}$. No período seco, para o Rio Ouricuri: OD: $\bar{x}=0,16 \mathrm{mg} / \mathrm{L} ; \mathrm{DBO}_{5}: \bar{x}=10 \mathrm{mg} / \mathrm{L} ; \mathrm{vazão:} \bar{x}=$ 0,93 mg/L; e temperatura: $\bar{x}=25^{\circ} \mathrm{C}$; para a anilha de efluentes: OD: $\bar{x}=0,43 \mathrm{mg} / \mathrm{L}, \mathrm{DBO}_{5}: \bar{x}=300 \mathrm{mg} / \mathrm{L}$, vazão: $\bar{x}=$ $0,88 \mathrm{~m} 3 / \mathrm{s}$ e temperatura: $\bar{x}=27^{\circ} \mathrm{C}$. Comparam-se os valores de OD, e DBO com a Resolução CONAMA 357/05, e verificou-se que estão em não conformidade, logo, o rio é considerado poluído tanto para potabilidade quanto para balneabilidade. Portanto, é necessário que os órgãos responsáveis no município utilizem dos dados aqui contidos para elaboração de medidas mitigatórias para a recuperação do rio.
\end{abstract}

Palavras-chave: Capanema; Recuperação; Rio Ouricuri; Simulação.

\begin{abstract}
The city of Capanema - PA, developed along the banks of the Ouricuri River. In view of this, it is important to know the capacity of self-depuration of this water resource. The objective of this research was to analyze quantitatively and qualitatively the simulation of the self-depuration capacity of this lotic environment, and to propose two mitigating measures for the reduction of the impacts generated in the hydric body and improvements in the quality of the water. The method was deductive, quantiqualitative in scope and applied in nature. The data obtained and analyzed, for the three points, $\mathrm{P} 1, \mathrm{P} 2$ and $\mathrm{P} 3$, in the rainy period: for Rio Ouricuri were, DO: $\mathrm{x}^{-}=0.26 \mathrm{mg} / \mathrm{L}$; $\mathrm{BOD} 5: \mathrm{x}^{-}=10 \mathrm{mg} / \mathrm{L}$; flow: $x^{-}=1.80 \mathrm{~m}^{3} / \mathrm{s}$; temperature: $\mathrm{x}^{-}=26^{\circ} \mathrm{C}$, for the effluent ring: $\mathrm{OD}: \mathrm{x}^{-}=0.16 \mathrm{mg} / \mathrm{L}, \mathrm{BOD} 5: \mathrm{x}^{-}=300 \mathrm{mg} / \mathrm{L}$; flow: $0.88 \mathrm{~m} / \mathrm{s}$; temperature: $\mathrm{x}^{-}=26^{\circ} \mathrm{C}$. In the dry period, for Ouricuri River: OD: $\mathrm{x}^{-}=0.16 \mathrm{mg} / \mathrm{L}$; BOD5: $\mathrm{x}^{-}=10 \mathrm{mg} / \mathrm{L}$; flow rate: $x^{-}=0.93 \mathrm{mg} / \mathrm{L}$; and temperature: $x^{-}=25^{\circ} \mathrm{C}$; for the effluent washer: OD: $x^{-}=0.43 \mathrm{mg} / \mathrm{L}, \mathrm{BOD}^{-}: \mathrm{x}^{-}=300$ $\mathrm{mg} / \mathrm{L}$, flow rate: $\mathrm{x}^{-}=0.88 \mathrm{~m}^{3} / \mathrm{s}$, and temperature: $\mathrm{x}^{-}=27{ }^{\circ} \mathrm{C}$. The values of $\mathrm{DO}$, and BOD are compared with the CONAMA Resolution 357/05, and it was found that they are in non-compliance, therefore, the river is considered
\end{abstract}


polluted for both potability and bathing. Therefore, it is necessary that the responsible bodies in the municipality use the data contained herein to develop mitigation measures for the recovery of the river.

Keywords: Capanema; Recovery; Ouricuri river; Simulation.

\section{Resumen}

El municipio de Capanema - PA, desarrollado a lo largo de las orillas del río Ouricuri. Por ello, es importante conocer la capacidad de autodepuración de este recurso hídrico. El objetivo de esta investigación fue analizar cuantitativamente, la simulación de la capacidad de autodepuración de este medio lótico, y proponer dos medidas mitigadoras para la reducción de los impactos generados en el cuerpo hídrico y mejoras en la calidad del agua. El método fue deductivo, de alcance cuantitativo y de carácter aplicado. Los datos obtenidos y analizados, para los tres puntos, P1, P2 y P3, en el periodo de lluvias: para el río Ouricuri fueron, DO: $\mathrm{x}^{-}=0,26 \mathrm{mg} / \mathrm{L}$; DBO5: $\mathrm{x}^{-}=10 \mathrm{mg} / \mathrm{L}$; caudal: $\mathrm{x}^{-}=1,80 \mathrm{~m}^{3} / \mathrm{s}$; temperatura: $\mathrm{x}^{-}=26^{\circ} \mathrm{C}$, para el anillo efluente: $\mathrm{OD}: \mathrm{x}^{-}=0,16 \mathrm{mg} / \mathrm{L}, \mathrm{DBO}: \mathrm{x}^{-}=300 \mathrm{mg} / \mathrm{L}$; caudal: $0,88 \mathrm{~m}^{3} / \mathrm{s}$; temperatura: $\mathrm{x}^{-}=26^{\circ} \mathrm{C}$. En el periodo seco, para el río Ouricuri: OD: $\mathrm{x}^{-}=0,16 \mathrm{mg} / \mathrm{L} ; \mathrm{DBO}$ : $\mathrm{x}^{-}=$ $10 \mathrm{mg} / \mathrm{L}$; caudal: $\mathrm{x}^{-}=0,93 \mathrm{mg} / \mathrm{L}$; $\mathrm{y}$ temperatura: $\mathrm{x}^{-}=25^{\circ} \mathrm{C}$; para el lavadero de efluentes: $\mathrm{OD}: \mathrm{x}^{-}=0,43 \mathrm{mg} / \mathrm{L}$, DBO5: $x^{-}=300 \mathrm{mg} / \mathrm{L}$, caudal: $\mathrm{x}^{-}=0,88 \mathrm{~m}^{3} / \mathrm{s}$ y temperatura: $\mathrm{x}^{-}=27{ }^{\circ} \mathrm{C}$. Los valores de DO, y DBO fueron comparados con la Resolución CONAMA 357/05, y se encontró que están en incumplimiento, por lo tanto, el río se considera contaminado tanto para la potabilidad como para el baño. Por lo tanto, es necesario que los organismos responsables del municipio utilicen los datos aquí contenidos para desarrollar medidas de mitigación para la recuperación del río.

Palabras-clave: Capanema; Recuperación; Río Ouricuri; Simulación.

\section{Introdução}

Os recursos hídricos se tornam foco da preocupação mundial devido à escassez em algumas regiões. Para o desenvolvimento de qualquer atividade é necessário o uso de água. Devido a lançamentos de efluentes doméstico e industriais não tratados, os ecossistemas aquáticos têm sido alterados de maneira significativa, e com isso, aumenta a concentração de matéria orgânica em um corpo hídrico, consequentemente, ela é a grande fonte de alimento para diversos organismos como, por exemplo, as algas (Vargas \& Marques, 2016).

A autodepuração pode ser entendida como um fenômeno ou processo de sucessão ecológica, em que há o restabelecimento do equilíbrio no meio aquático como um dos mecanismos essencialmente naturais (von Sperling, 2011). Ela está vinculada ao restabelecimento do equilíbrio no meio aquático. Para tanto, são necessários levantamentos de campo na área em estudo, para obtenção dos dados necessários para a avaliação da capacidade de autodepuração (Guedes, 2009) que permitam a avaliação da poluidora que são os efluentes lançados no corpo hídrico (Viveiros, 2009).

$\mathrm{Na}$ extensão de um corpo hídrico, a autodepuração é um processo que se apresenta quatro estágios: 1) Zona de degradação, onde há uma diminuição do consumo de oxigênio $(\mathrm{O})$; 2) Zona de decomposição ativa, com predomínio de micro-organismos decompositores; 3) Zona de recuperação, com tendência de elevação nos teores de oxigênio; e 4) Zona de águas limpas, onde há maior concentração de oxigênio dissolvido e vida aquática (Andrade, 2010).

Os rios são classificados como ambientes lóticos em razão da contínua movimentação e em estreita associação com sua bacia de drenagem, que podem ser considerados, ecológica e hidrologicamente, um sistema de fluxos. O ambiente circundante também exerce um importante papel sobre o sistema aquático como, por exemplo, a correnteza que também pode ser salientada com uma importante ação sobre o transporte de material orgânico, sobre a natureza do leito, sobre a oxigenação das águas e sobre a distribuição dos organismos (Uieda, 2011).

Em relação ao ambiente circundante, deve-se lembrar sempre que a maioria dos 5.564 municípios brasileiros tem origem às margens de rios. Todavia o desenvolvimento econômico e populacional provoca supressão da mata ciliar, uso e ocupação do solo efetuada sem planejamento, eleva os riscos a inundações, e poluição ou contaminação dessas águas e, como consequência disso, pode haver perda da capacidade de autodepuração (Santiago et al., 2020).

O contexto histórico dessas perdas mostram que um dos serviços hidráulicos de maior importância nessa evolução, o saneamento básico, não acompanhou aqueles crescimentos, e em particular, não manteve a coleta de águas residuais 
domésticas efetivas que, até hoje, na maioria dos municípios brasileiros, ainda são despejadas nos rios que circundam ou perpassam pelas áreas urbanas deles, contribuindo para a diminuição da qualidade da água deles (Cordeiro et al., 2020).

Para verificação, controle, e tomadas de ações que remediem esses impactos, atualmente, há métodos de avaliação dos ambientes lóticos eficientes no diagnóstico ambiental, além da objetividade na interpretação do estado ambiental dele, e de baixo custo, porém sem perder a qualidade da informação (Carvalho et al., 2013). Eles permitem a compreensão dos processos que governam o funcionamento dos ecossistemas fluviais que são imprescindíveis para nortear o planejamento de projetos que possam minimizar os efeitos antrópicos sobre ambientes lóticos (Siqueira \& Henry-Silva, 2011).

Ademais, a característica natural de um ambiente lótico pode ser mensurada pela presença de agentes orgânicos (matéria orgânica) e inorgânicos (teor dos sólidos minerais), em diferentes quantidades, composição e também pela diversidade da comunidade aquática presentes no ecossistema, cujas particularidades deste ambiente estão sujeitas a variações estruturais e sazonais provenientes de fatores particularmente internos (Oxigênio Dissolvido - OD) e externos (irradiação solar) do próprio curso d'água (Silva et al., 2016).

Já a Demanda Bioquímica de Oxigênio (DBO), é um indicador de matéria orgânica associada a concentração de oxigênio consumido que atua na oxidação da matéria orgânica, biodegradável ou não, geralmente em meio ácido, com ação de uma substância química com alto poder oxidante (Valente et al., 1997). Ela é um parâmetro para o monitoramento da qualidade da água, onde os valores mais altos podem significar mais poluentes orgânicos na água. Por isso é utilizado para a avaliação da qualidade da água que, fornece informações sobre a quantidade de cargas orgânicas presentes na água (Jouanneau et al., 2014).

Em relação aos cálculos dessas quantidades, já estão sendo aplicados modelos matemáticos (Batista \& Cabral, 2017; Miranda et al., 2016; Poletti \& Cunha, 2017) como ferramenta importante para simular e avaliar as mudanças físicas, químicas e biológicas que ocorrem em sistemas aquáticos. É um poderoso instrumento de gestão que auxilia em tomada de decisões, por meio de modelos é possível gerar cenários futuros, estabelecer planos de gestão, projetar os prováveis impactos ambientais e estimar os custos das medidas a serem tomadas (Vargas \& Marques, 2015).

Dentre tantos modelos matemáticos em uso, destaca-se o de Streeter-Phelps, pois ele permite avaliar a capacidade de autodepuração de rios, ou seja, para analisar a recuperação da degradação sofrida no corpo hídrico (Sales, 2014). Deve-se observar também a ocupação inadequada de unidades arquitetônicas sejam elas, residenciais e comerciais próximos aos mananciais, que promovem o lançamento de resíduos e o uso desordenado das águas que podem proporcionar risco a saúde humana e comprometer de forma irreversível a estabilidade físico-química e o ciclo hidrológico do corpo d'água (Alvarenga et al., 2012).

Após todas essas observações, deve-se promover um comparativo com os conteúdos legislativas inerentes ao impactos analisados como, por exemplo, a resolução do Conselho Nacional de Meio Ambiente (CONAMA) n. 357 (2005) cujas diretrizes são: classificação e as condições constituídas à manutenção da qualidade dos corpos hídricos e estabelece padrões e condições de lançamento de efluentes menos exigentes. Já na resolução de n. ${ }^{\circ} 430$ (2011), foram estabelecidas as condições, parâmetros, diretrizes e padrões de lançamento de efluentes. Na resolução determina que os efluentes só podem ser despejados em corpo hídrico se as metas obrigatórias constituídas para cada corpo d'água estiver de acordo com seu respectivo enquadramento.

Todos esses fatos justificam este estudo e incrementam a relevância dessa pesquisa, pois irá gerar dados sobre a qualidade do rio Ouricuri, Capanema - PA, o que permitirá às autoridades locais, elaborar soluções compatíveis com o estado de autodepuração desse rio, e sugerir medidas para tratar o lançamento de efluentes lançados no mesmo.

Além disso, tanto a justificativa quanto a relevância contribuíram para a elaboração do objetivo: realização de análise quanti-qualitativa quanto a simulação da capacidade de autodepuração do ambiente lótico denominado rio Ouricuri, munícipio 
de Capanema - PA, e proposição de duas medidas mitigatórias para a redução dos impactos gerados no corpo hídrico e melhorias na qualidade da água.

\section{Material e métodos}

\subsection{Fisiografia do município}

O município de Capanema $\left(01^{\circ} 11^{\prime} 45^{\prime} \mathrm{S} ; 47^{\circ} 10^{\prime} 51^{\prime} \mathrm{W}\right)$ está localizado (Figura 1) na mesorregião do nordeste paraense, microrregião Leste paraense da zona bragantina, distante $160 \mathrm{~km}$ da capital do estado, Belém. É considerado o município mais desenvolvido dessa zona. A extensão territorial é de aproximadamente 614,693 mil km², tendo população igual a 67,150 mil habitantes no ano de 2017, com projeção para 69.431 mil em 2020 (IBGE, 2017).

Figura 1. Mapa político e planimétrico com os limites políticos do município de Capanema, Nordeste do estado do Pará, Brasil.

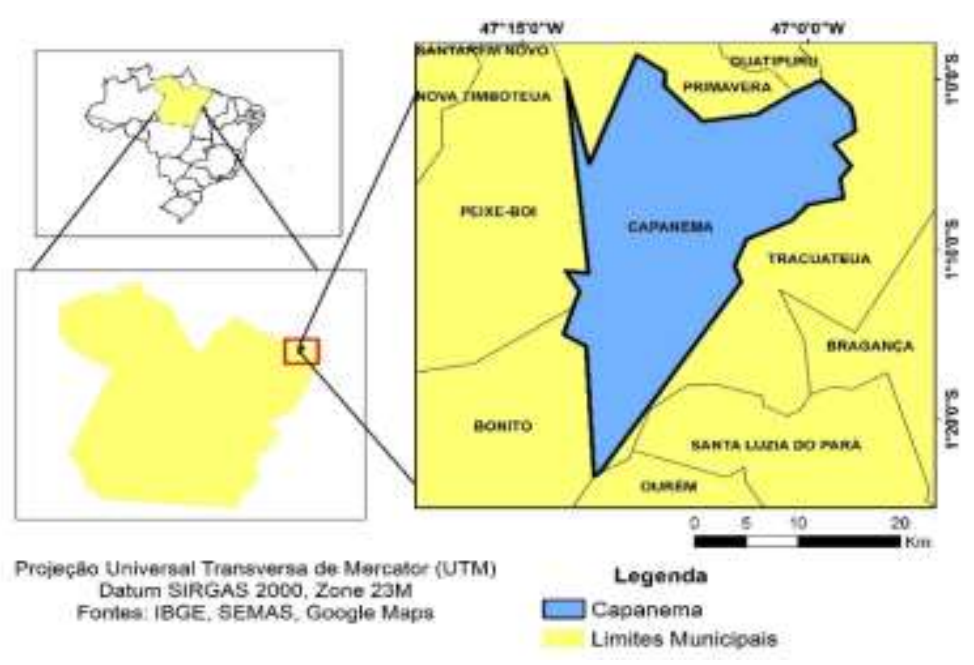

Fonte: Autores (2020).

A cidade desenvolveu-se às margens do rio Ouricuri que, a princípio, era ocupado por populações rurais dispersas e com hipossuficiência econômica. O rio é considerado o principal afluente a transpor o município no sentido Leste-Oeste, tendo uma extensão de $18 \mathrm{~km}$, sendo que $7 \mathrm{~km}$ percorrem a sede municipal (Costa et al., 2016).

Em relação a ocupação inadequada e/ou sem planejamento, ocorreu no município de Capanema, semelhante aos demais municípios brasileiros. A ocupação do território capanemense é marcada por uma notável supressão vegetal voltada para a disponibilização de locais habitáveis, tornando evidente a separação entre áreas urbanas e rurais. Assim, esse processo em Capanema foi responsável por grande parte da degradação ambiental dos recursos naturais como, por exemplo, o rio Ouricuri (Lima, 2015).

O município apresenta a cobertura vegetal primitiva de Floresta Densa dos baixos platôs Pará/Maranhão sendo que foi praticamente substituída pela Floresta Secundária ou de Capoeira devido aos desmatamentos para plantio de espécies agrícolas e por campos artificiais devido à pecuária. Em relação aos solos são representados por: Latossolo Amarelo, textura média, Concrecionários Lateríticos, Areia Quartsoza, Latossolo Amarelo e Podzol Hidromórfico, e solos Hidromórficos Indiscriminados e solos aluviais (Pará, 2016).

O tipo de clima típico da Amazônia de acordo com a classificação de Koppen traduz como clima quente e úmido que ocorre em duas estações bem definidas: o período chuvoso que ocorre entre os meses de fevereiro a maio e, o período seco de 
junho a novembro. A média anual da precipitação pluviométrica está em torno de $2.428 \mathrm{~mm}$. A variação de temperatura máxima está entre $29^{\circ} \mathrm{C}$ e $31^{\circ} \mathrm{C}$ e a temperatura média aproximadamente $26^{\circ} \mathrm{C}$ (Vieira et al., 2018).

\subsection{Método}

O método utilizado foi o dedutivo (Matias-Pereira, 2016), pois, há duas premissas verdadeiras que nortearam esse estudo: (1) o crescimento urbano desordenado interfere na capacidade de autodepuração dos corpos hídricos, consequentemente, (2) determina a perda da potabilidade desse recurso natural. Esse método foi associado ao estatístico porque Pereira et al.(2018), sintetizaram que se pode reduzir dados sociais e político-econômicos a quantidades e, em seguida, comprovar as relações entre eles.

Ainda de acordo com os argumentos desses autores, o método quantitativo permite a geração de dados via mensurações seguidas de unidades inerentes a elas, e a análise deles é efetuada em porcentagens, aplicações estatísticas como Descritiva, além de equações matemáticas já existentes.

\subsection{Coleta de dados}

\subsubsection{Primários}

Para a obtenção desses dados, foi estabelecida extensão urbana do rio Ouricuri, em 1.020,64 m, maior comprimento da faixa em área urbana, portanto, maior probabilidade de impactos tanto no corpo hídrico quanto nas margens direita e esquerda. As coletas de água foram efetuadas em três pontos: P1 (Figura 2a), P2 (Figura 2b) e P3 (Figura 2b) do Rio Ouricuri, em dois períodos sazonais: chuvoso (maio); seco ou menos chuvoso (novembro). A justificativa para a escolha dos pontos de coleta: localização deles e a carga de efluentes domésticos que recebem nessa extensão. Em seguida, foram mensuradas, in situ, as variáveis de monitoramento adequadas para avaliação da autodepuração: Oxigênio Dissolvido (OD), e Temperatura $\left({ }^{\circ} \mathrm{C}\right)$ com o Multiparâmetro marca Datta Logger modelo WA - 2015 (Figura 2D).

Figura 2. Pontos de coleta da água superficial nos pontos: A) P1; B) P2; C) P3; D) Aparelho digital para mensuração de dois parâmetros limnológicos: OD (mg/L); T $\left({ }^{\circ} \mathrm{C}\right)$, rio Ouricuri. Capanema, Pará, Brasil.

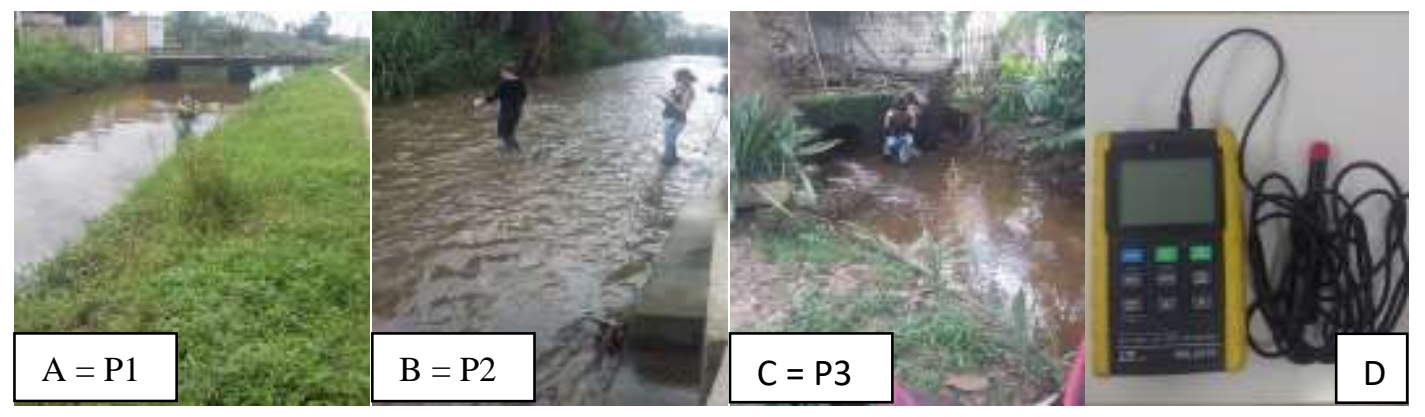

Fonte: Autores (2020).

O aparelho foi calibrado pelo fornecedor com certificação e a Vazão $(\mathrm{Q})$ através do método do flutuador. Os valores de Demanda Bioquímica de Oxigênio (DBO) do rio foi mensurado pelo software D’ÁGUA 2.0 e os valores médios do esgoto doméstico bruto (200 < EDB > $500 \mathrm{mg} / \mathrm{L}$ ), para quatro variáveis limnológicas (Quadro 1), foram realizadas de acordo com o sintetizado por von Sperling (2009). 
Quadro 1. Variáveis limnológicas mensuradas para a pesquisa e seus objetivos.

\begin{tabular}{|c|l|}
\hline Variáveis mensuradas & \multicolumn{1}{|c|}{ Objetivo } \\
\hline $\begin{array}{c}\text { Oxigênio Dissolvido } \\
(\mathrm{OD})\end{array}$ & $\begin{array}{l}\text { Identificar a concentração de oxigênio presente no corpo hídrico } \\
\text { sendo um dos principais dados de entrada no cálculo da } \\
\text { autodepuração no modelo matemático de Streeter-Phelps. }\end{array}$ \\
\hline $\begin{array}{c}\text { Demanda Bioquímica } \\
\text { de Oxigênio }\left(\mathrm{DBO}_{5}\right)\end{array}$ & $\begin{array}{l}\text { Identificar a quantidade necessária para a estabilização da matéria } \\
\text { orgânica sendo utilizado como dados de entrada no cálculo de } \\
\text { autodepuração do modelo que será utilizado para o cálculo. }\end{array}$ \\
\hline Vazão $(\mathrm{Q})$ & $\begin{array}{l}\text { A vazão será utilizada para o cálculo de autodepuração no modelo } \\
\text { matemático estudado. }\end{array}$ \\
\hline Temperatura $\left({ }^{\circ} \mathrm{C}\right)$ & Apresentar as condições atuais do rio. \\
\hline
\end{tabular}

Fonte: Autores (2020).

O sentido da amostragem da água para exames laboratoriais ocorreu no contrafluxo (jusante-montante), sentido sulnorte, em três pontos (P1, P2, P3) com distâncias não simétricas devido a irregularidade sofrida pelo meandro desse corpo hídrico (Figura 3).

Figura 3. Localização dos três pontos de coleta de água superficial. Rio Ouricuri, Capanema, Pará, Brasil.

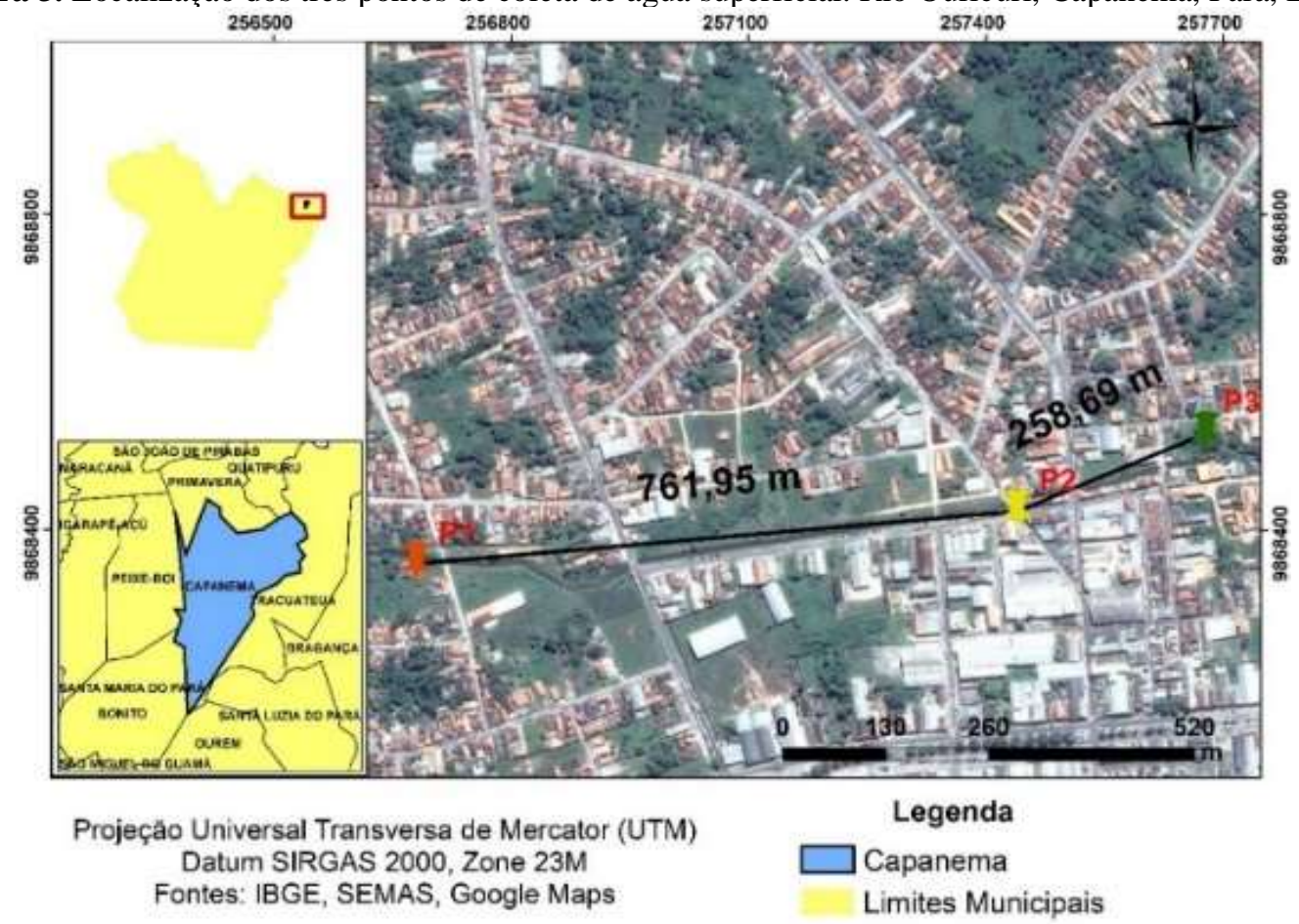

Fonte: Autores (2020).

Devido às características do escoamento superficial de cada ponto, foi possível realizar as mensurações a partir do contato direto do sensor do aparelho medidor no corpo hídrico $(\mathrm{P}=15 \mathrm{~cm})$ Segundo o manual de instruções do equipamento, cursos d'água com velocidade de escoamento de pelo menos $30 \mathrm{~cm}(12$ ' ')/s oferecem condições ideais para este tipo de procedimento. Para obtenção dos dados primários acerca da vazão, aplicaram-se cinco etapas (Figura 4). 
Figura 4. Fluxograma das etapas realizadas.

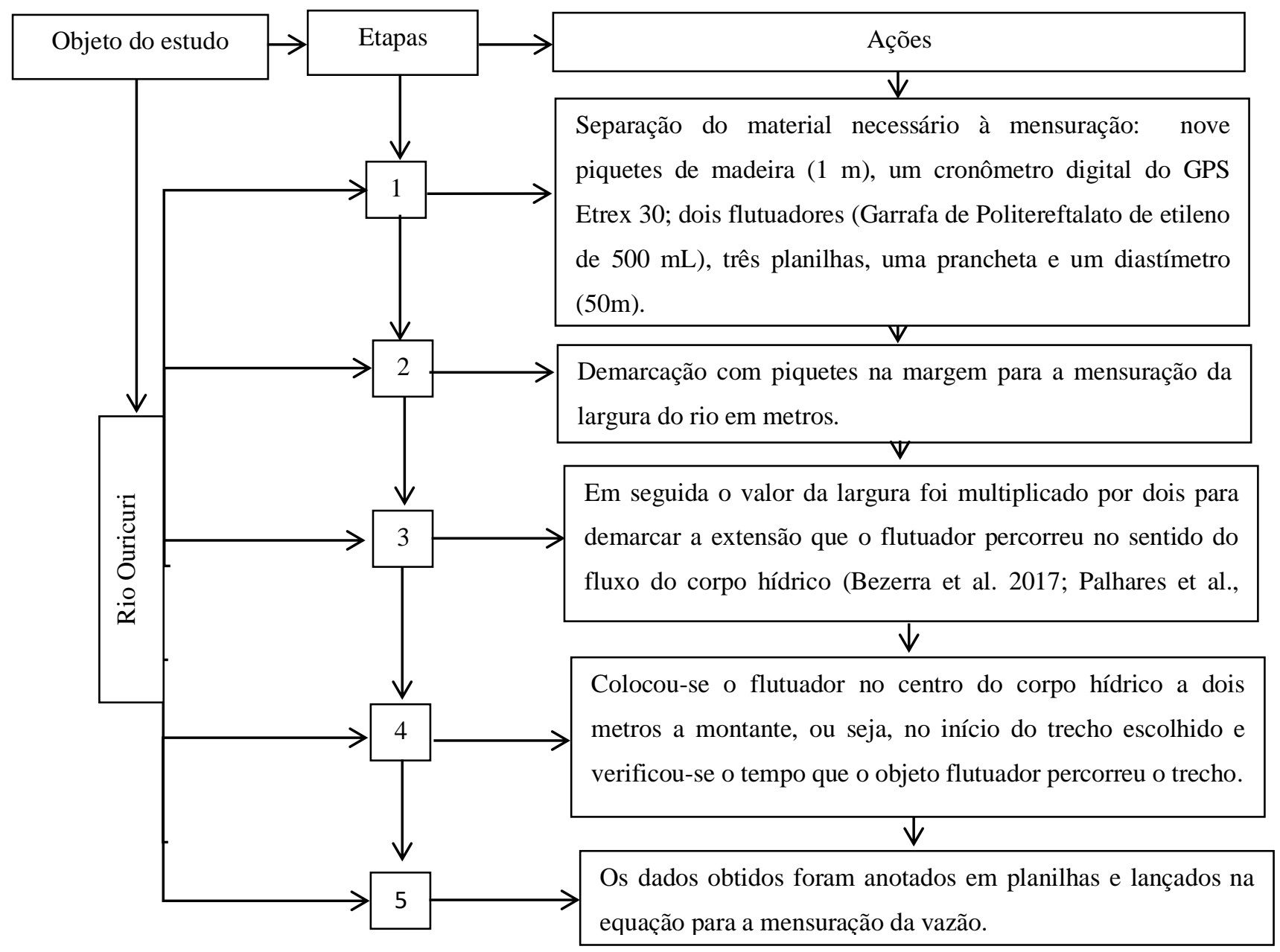

Fonte: Autores (2020).

Os dados secundários foram obtidos a partir do Levantamento de dados documentais, cujo recorte temporal, situou-se em 2009 a 2018, para que, fossem obtidas informações mais recentes, ou seja, da última década, em sites de acesso livre: Elsevier, Portal de Periódicos da Coordenação de Aperfeiçoamento de Pessoal do Nível Superior (CAPES); Scientific Eletronic Library Online (SciELO); WebScience. Vale ressaltar que esse tema requereu complementação a partir de literaturas pioneiras publicadas em 1925,1996 e 2005, além das legislações ambientais hídricas: Resoluções CONAMA: n. ${ }^{\circ} 274$ (2000), n. ${ }^{\circ} 357$ (2005) e n. ${ }^{\circ} 430$ (2011).

\subsection{Cálculos efetuados}

Foram efetuados cálculos para vazão, esgotamento de efluentes, autodepuração. DBO, OD, com o uso de equações já existentes (Quadro 2). 
Quadro 2. Técnicas e equações empregadas para os cálculos das variáveis da autodepuração.

\begin{tabular}{|c|c|}
\hline $\begin{array}{c}\text { Mensuração; } \\
\text { Técnica (Origem) }\end{array}$ & Equações \\
\hline \multirow[b]{2}{*}{$\begin{array}{l}\text { Vazão do rio; do flutuador } \\
\text { (Bezerra et al, 2017; Palhares } \\
\text { et al., 2007). }\end{array}$} & $Q=\frac{C A \cdot I \cdot C J}{T}$ \\
\hline & $\begin{array}{l}\text { Onde: } \mathrm{A}=\text { média da área do rio, sendo calculado pelas distâncias } \\
\text { entre as margens e multiplicada pela profundidade do rio; } \mathrm{L}=\text { largura } \\
\text { do trecho, ou seja, é o comprimento da área de medição; } \mathrm{C}= \\
\text { coeficiente ou fator de correção em que, se utiliza } 0,9 \text { para rios com } \\
\text { fundo barrento; } \mathrm{T}=\text { tempo que o flutuador leva para se deslocar no } \\
\text { comprimento, em segundos. }\end{array}$ \\
\hline $\begin{array}{l}\text { 1Vazão do esgotamento de } \\
\text { efluentes nas anilhas } \\
\text { (von Sperling, 2005). }\end{array}$ & $\begin{array}{l}\text { Determinação per capita de consumo de água x ligações domiciliares } \\
\text { (Quadro 3). }\end{array}$ \\
\hline $\begin{array}{l}\text { Coeficiente de retorno }(\mathbf{R} \%) \\
\text { A partir da água fornecida que } \\
\text { adentra a rede de coleta na } \\
\quad \text { forma de esgoto } \\
\text { (von Sperling, 2005) }\end{array}$ & 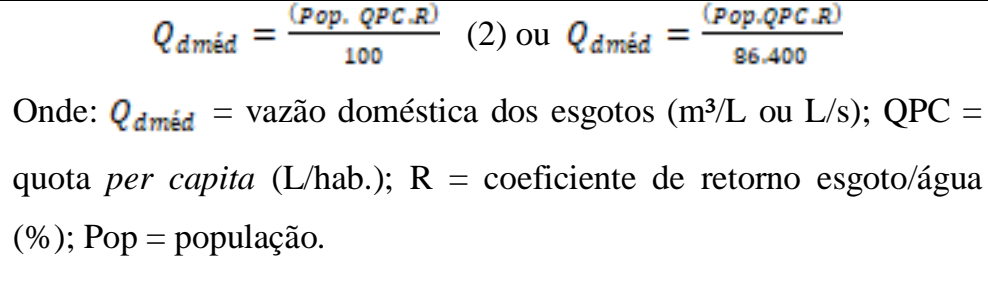 \\
\hline $\begin{array}{l}\text { ³Autodepuração } \\
\text { (Street-Phelps, 1925; Santos et } \\
\text { al., 2010). }\end{array}$ & $\begin{array}{l}\text { Aplicação do software AD’ÁGUA } 2.0 \text { (Figura 5) } \\
\text { (DBO, OD e a vazão do rio e do esgoto) }\end{array}$ \\
\hline \multicolumn{2}{|c|}{ CÁLCULOS COMPLEMENTARES PARA AUTODEPURAÇÃO } \\
\hline \multirow[t]{2}{*}{ (von Sperling, 2005) } & $\begin{array}{l}\text { Dados complementares: Vazão do curso d'água (Qr); Vazão de } \\
\text { esgotos (Qe); Oxigênio dissolvido no rio, à montante do lançamento } \\
\text { (ODr); Oxigênio dissolvido no esgoto (Ode); } \mathrm{DBO}_{5} \text { no rio, à } \\
\text { montante do lançamento (DBOr); } \mathrm{DBO}_{5} \text { do esgoto (DBOe); } \\
\text { Coeficiente de desoxigenação }\left(K_{1}\right)\end{array}$ \\
\hline & $\begin{array}{l}\qquad D B O_{T}=L_{0}-e^{-K_{1} t} \\
\text { Onde: } D B O_{\mathrm{t}} \text { é a quantidade de Oxigênio Dissolvido consumido desde } \\
\text { o instante inicial até o instante t; } L_{0} \text { : é a DBO imediata após o ponto } \\
\text { de lançamento, ou seja, a quantidade total de Oxigênio necessária } \\
\text { para a completa estabilização da matéria orgânica; } K_{1} \text { : é a constante } \\
\text { de desoxigenação dependendo do tipo do efluente; t: tempo em dias }\end{array}$ \\
\hline
\end{tabular}


Continuação do Quadro 2. Técnicas e equações empregadas para os cálculos das variáveis da autodepuração.

\begin{tabular}{|c|c|}
\hline $\begin{array}{c}\text { Mensuração; } \\
\text { Técnica (Origem) }\end{array}$ & Equações \\
\hline $\begin{array}{l}\text { Oxigênio Dissolvido (OD). } \\
\text { (Santos et al., 2010; Streeter- } \\
\text { Phelps, 1925) }\end{array}$ & $\begin{array}{l}\qquad C_{t}=C_{S}-D_{T} \text { (5) } \\
\text { Onde: Concentração de oxigênio ao longo do tempo }\left(\mathrm{C}_{\mathrm{T}}\right) \text {; } \\
\text { Concentração de saturação do oxigênio }\left(\mathrm{C}_{\mathrm{S}}\right) \text {; déficit inicial de OD no } \\
\text { ponto de mistura }\left(D_{\mathrm{T}}\right)\end{array}$ \\
\hline $\begin{array}{l}\text { Oxigênio Dissolvido (OD) } \\
\text { em função to tempo } \\
\text { (Streeter-Phelps, 1925) }\end{array}$ & 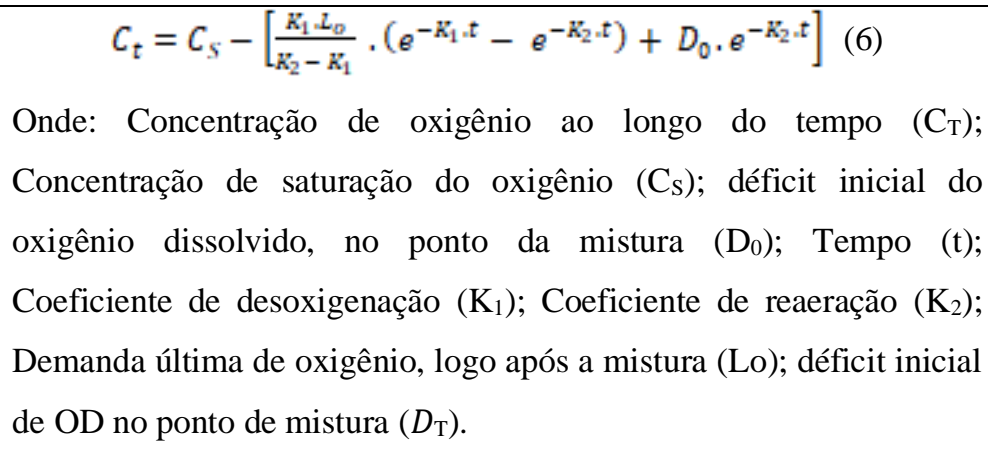 \\
\hline $\begin{array}{c}\text { Coeficiente de } \\
\text { desoxigenação - K1 } \\
\text { (von Sperling, 2005) }\end{array}$ & $\begin{array}{l}\text { Em águas residuárias o valor de } \mathbf{K} \mathbf{1} \text { corresponde a } 0,45 \text {, ou seja, de } \\
\text { acordo com os valores genéricos, base e } 20^{\circ} \mathrm{C} \text { para vários tipos de } \\
\text { efluentes. Este valor será aplicado apenas na anilha de efluentes. } \\
\text { ( Tabela } 1 \text { ) }\end{array}$ \\
\hline $\begin{array}{l}\text { Coeficiente de dexogenação } \\
\text { corrigido - K1t } \\
\text { (von Sperling, 2005; } \\
\text { Santos, 2018). }\end{array}$ & $\begin{array}{l}\qquad K_{1}=k_{1_{20}} \cdot \theta^{[T-20])} \\
\text { Usualmente, o valor empregado de } \theta \text { é } 1,047(1) \text {, isso quer dizer, que } \\
\text { o valor de } \mathrm{K} 1 \text { aumenta } 4,7 \% \text { a cada acréscimo de } 1^{\circ} \mathrm{C} \text { na temperatura } \\
\text { (T) da água (2) }\end{array}$ \\
\hline $\begin{array}{l}\text { 4) Coeficiente de reaeração - } \\
\qquad \text { K2 } \\
\text { (Queiroz et al., 2015). }\end{array}$ & $\begin{array}{l}\text { Em função da profundidade }(\mathrm{H}) \text { e velocidade }(\mathrm{V}) \text { do curso d'água } \\
\text { está de acordo com os modelos baseados em dados hidráulicos (base } \\
\text { e } 20^{\circ} \mathrm{C} \text { ). } \\
\text { ( Tabela } 2)\end{array}$ \\
\hline $\begin{array}{c}\text { Coeficiente de reaeração } \\
\text { corrigido }-\mathbf{K}_{\mathbf{2 t}} \\
\text { (Santos et al., 2010) }\end{array}$ & $\begin{array}{c}\qquad K_{2_{T}}=k_{2_{20}} \times \theta^{[T-20]}(8) \\
\text { Utilizado do coeficiente de temperatura } \theta \text { é } 1,024\end{array}$ \\
\hline
\end{tabular}

${ }^{1}$ Valor considerado anualmente devido a faixa populacional para ser utilizada nos dois períodos do ano: chuvoso e seco. ${ }^{2}$ Atuam diretamente na capacidade de transporte e diluição do corpo hídrico analisado. Fonte: Autores. 
Quadro 3. Faixas com consumo per capita de água.

\begin{tabular}{|l|c|c|}
\hline Porte da Comunidade & Faixa populacional & $\begin{array}{c}\text { Consumo per capita } \\
\text { (L/hab.d) }\end{array}$ \\
\hline Povoado rural & $<5.000$ & $90-140$ \\
\hline Vila & $5.000-10.000$ & $100-160$ \\
\hline Pequena localidade & $10.000-50.000$ & $110-180$ \\
\hline Cidade média & $50.000-25.000$ & $120-220$ \\
\hline Cidade grande & $>250.000$ & $150-300$ \\
\hline
\end{tabular}

Fonte: Autores, com dados extraídos de (von Sperling, 2005).

Tabela 1. Valores genéricos de K1 (base e $20^{\circ}$ ) para diversos tipos de efluentes.

\begin{tabular}{lc}
\hline Origem & $\boldsymbol{K}_{\mathbf{1}}\left(\boldsymbol{d}^{-\mathbf{1}}\right)$ \\
\hline Água residuárias concentrada & $0,35-0,45$ \\
Água residuária de baixa concentração & $0,30-0,40$ \\
Efluente primário & $0,30-0,40$ \\
Efluente secundário & $0,12-0,24$ \\
Efluente terciário & $0,10-0,20$ \\
Rios com águas limpas & $0,09-0,21$ \\
\multicolumn{1}{c}{ Água para abastecimento público } & $<12$ \\
\hline
\end{tabular}

Fonte: Autores, com dados extraídos de (von Sperling, 2005).

Tabela 2. Valores típicos de $\mathrm{K}_{2}$ (base e $20^{\circ} \mathrm{C}$ ) para corpos hídricos.

\begin{tabular}{lcc}
\hline \multicolumn{1}{c}{ CORPO D'ÁGUA } & \multicolumn{2}{c}{$\mathbf{K}_{\mathbf{2}}\left(\mathbf{d}^{\mathbf{1}}\right)$} \\
\cline { 2 - 3 } & PROFUNDO & RASO \\
\hline Pequenas Lagoas & 0,12 & 0,23 \\
\hline Rios Vagarosos, grandes lagos & 0,23 & 0,37 \\
\hline Grandes rios com baixa velocidade & 0,37 & 0,36 \\
\hline Grandes rios com velocidade normal & 0,46 & 0,69 \\
\hline Rios rápidos & 0,69 & 1,15 \\
\hline Corredeiras e quedas d'água & $>1,15$ & $>1,61$
\end{tabular}

Fonte: Autores, com dados extraídos de (von Sperling, 2005). 
Figura 5. Área de trabalho do software AD’ÁGUA 2.0.

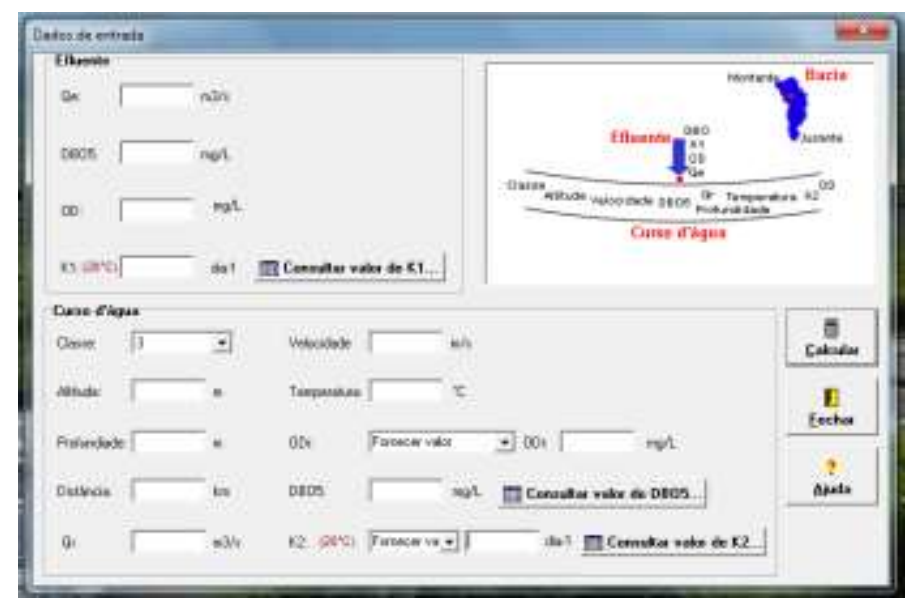

Fonte: Silva et al (2016).

\subsection{Análise estatística dos dados.}

O tratamento estatístico dos dados foi efetuado com o uso de planilhas eletrônicas contidos no software Excel versão 2016 (MICROSOFT CORPORATION, 2016), e aplicação da Estatística Descritiva (média e desvio padrão). A plotagem gráfica foi realizada com o software AD’ÁGUA 2.0 (Santos et al., 2010). Por fim comparam-se os valores para as médias obtidas em função da normatização contida nas Resoluções CONAMA: n. 274 (2000), n. ${ }^{\circ} 357$ (2005) e n. ${ }^{\circ} 430$ (2011).

\section{Resultados e Discussão}

\subsection{Capacidade de autodepuração}

\subsubsection{Oxigênio dissolvido (OD)}

A análise de dados obtidos indicou que há tendências de variação para os valores médios de OD nos dois períodos analisados, e nos três pontos de mensurações (Tabela 3), tanto no rio quanto na anilha de efluentes, nos períodos chuvoso e seco.

Tabela 3. Valores $($ Máximo $=$ Vmáx; Mínimo $=$ Vmín; Média e Desvio Padrão $(\bar{x} \pm \sigma)$ para o Oxigênio Dissolvido (OD, em mg/L), ns períodos chuvoso (P.C) e seco (P.S) do rio Ouricuri e da anilha de efluentes. Capanema, Pará, Brasil.

\begin{tabular}{|c|c|c|c|c|c|c|}
\hline & \multicolumn{3}{|c|}{ Rio Ouricuri } & \multicolumn{3}{|c|}{ Anilha de efluentes } \\
\hline & \multicolumn{2}{|l|}{ P.C. } & P.S. & \multicolumn{2}{|l|}{ P.C. } & \multirow{2}{*}{$\begin{array}{c}\text { P.S. } \\
\text { lo-.- }\end{array}$} \\
\hline & \multicolumn{3}{|c|}{-------Encontrado------ } & \multicolumn{2}{|c|}{-------Encontrado------ } & \\
\hline & 0,5 & Vmáx. & 0,6 & 0.2 & Vmáx. & 0.6 \\
\hline Padrão 357/05 & 0,1 & Vmín. & 0,2 & 0.1 & Vmín. & 0.2 \\
\hline$>\mathbf{4 , 0}$ & $0,3 \pm 0.2$ & $\bar{x} \pm \sigma$ & $0,4 \pm 0.2$ & $0,2 \pm 0.0$ & $\bar{x} \pm \sigma$ & $0,4 \pm 0.4$ \\
\hline
\end{tabular}

Fonte: Autores (2020).

As concentrações de Oxigênio Dissolvido do rio no período chuvoso $(0,26 \mathrm{mg} / \mathrm{L})$ e no período seco $(0,16 \mathrm{mg} / \mathrm{L})$ estão abaixo do padrão estipulado (não deve ser inferior a $4 \mathrm{mg} / \mathrm{L}$ ) para rio de classe III. Em relação a anilha de efluentes, os valores obtidos (período chuvoso $=0,2 \mathrm{mg} / \mathrm{L}$; período seco $=0.4 \mathrm{mg} / \mathrm{L}$ ) mostraram tendências de variações para mais ou para menos 
quando comparados com aqueles obtidos para o rio Ouricuri. A baixa concentração OD disponível no corpo hídrico, indica que o rio recebe e decompõe grande quantidade de matéria orgânica oriundos da anilha de efluentes domésticos.

Oliveira et al.(2018) na cidade de Mossoró - RN, efetuaram estudo sobre as concentrações de OD e concluíram que os baixíssimos níveis de OD, estão relacionados ao processo de decomposição da matéria orgânica. Na pesquisa realizada em Capanema, os dados obtidos para o OD indicaram que, no rio Ouricuri, ocorre a decomposição da matéria orgânica via anilha de efluentes. Com isso, os dados obtidos nessa pesquisa corroboram com aqueles encontrados em Mossoró.

Já em Manaus - AM, Silva (2012), efetuou estudos acerca das variações de vários parámetros hidrícos, dentre eles, o $\mathrm{OD}$, e conclui que no período seco devido a maior taxa fotossintética planctônica bem como uma diminuição no aporte de sedimentos. Como os padrões de OD no rio Ouricuri foram elevados, isso pode ter ocorrido. No Rio Negro - AM, Arcos et al. (2020), realizam pesquisas acerca do problema com coliformes fecais, e uma das variáveis analisadas foi o OD. Esses pesquisadores obtiveram dados que os permitiram escrever que, no período da seca (Vmáx=6,9 mg/L; Vmín = 5,7 mg/L), foi inferior ao da cheia (Vmáx. = 7,6 mg/L; Vmín. = 7,1 mg/L).

\subsubsection{Demanda Bioquímica de Oxigênio}

Os parâmetros mensuráveis para a Demanda Bioquímica de Oxigênio (DBO), indicaram valores médios, para o rio, igual a $10 \mathrm{mg} / \mathrm{L}$; anilha de efluentes, equivaleu a $300 \mathrm{mg} / \mathrm{L}$, isso para os dois períodos analisados (Tabela 4).

Tabela 4. Valores (Máximo $=$ Vmáx.; Mínimo $=$ Vmín; média e desvio padrão $=\bar{x} \pm \sigma$ ) para a Demanda Bioquímica de Oxigênio (DBO em mg/L) do Rio Ouricuri e da anilha de efluentes nos períodos chuvoso (P.C) e seco (P.S.). Capanema, Pará, Brasil.

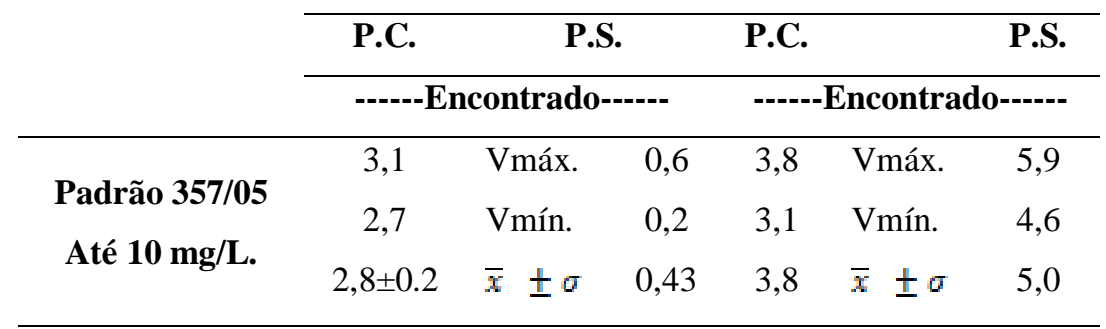

Fonte: Autores (2020).

Quando comparado com valores normativos pela resolução CONAMA n. ${ }^{\circ} 357$ (2005), houve indicação de que o rio é considerado antropizado, pois, recebe diretamente despejos de efluentes domésticos sem tratamento, de origem principalmente orgânica por conter residências e comércios às suas margens, esse teor orgânico eleva os índices de $\mathrm{DBO}_{5}$, e diminui os níveis de OD.

Na pesquisa realizada no córrego Água Branca, em Itirapina-SP, por Moruzzi et al. (2012) eles obtiveram dados que os permitiram identificar tendência de elevação no teor de DBO num corpo d'água, especialmente provocados por despejos de origem predominantemente orgânica. Em Capanema, o índice de DBO mostrou-se elevado por tratar de esgoto doméstico bruto (300 mg/L), logo, esse valor é oriundo de matéria orgânica depositada no corpo hídrico.

\subsubsection{Vazão}

Os dados obtidos e analisados para vazão no rio Ouricuri no período chuvoso $\left(1,80 \mathrm{~m}^{3} / \mathrm{s}\right)$ e no período seco $(0,93$ $\left.\mathrm{m}^{3 / \mathrm{s}}\right)$; na anilha de efluentes os valores obtidos indicaram $\left(0,88 \mathrm{~m}^{3} / \mathrm{s}\right)$ indicaram tendência a estabilidade nos dois analisados (Tabela 5). 
Tabela 5. Valores (Máximo = Vmáx.; Mínimo $=$ Vmín; média e desvio padrão $=\bar{x} \pm \sigma$ ) para a vazão $\left(\mathrm{m}^{3} / \mathrm{s}\right)$ do Rio Ouricuri e da anilha de efluentes nos períodos chuvoso (P.C) e seco (P.S.). Capanema, Pará, Brasil.

\begin{tabular}{ccccc}
\hline \multicolumn{2}{c}{ Rio Ouricuri } & \multicolumn{2}{c}{ Anilha de efluentes } \\
\hline & P.C. & P.S. & P.C. & P.S. \\
\hline Vmáx. & 2,7 & 1,3 & 0,0 & 0,0 \\
\hline Vmín. & 2,7 & 0,2 & 0,0 & 0,0 \\
\hline $\bar{x} \pm \sigma$ & $1,8 \pm 1.3$ & $0,9 \pm 0.6$ & $0,0 \pm 0.0$ & $0,0, \pm 0.0$ \\
\hline
\end{tabular}

Fonte: Autores (2020).

No corpo hídrico, a explicação para a redução da vazão é a diminuição na taxa da precipitação e na elevação da temperatura do ar que provoca maior taxa de evaporação $\left(26^{\circ} \mathrm{C}\right)$. Vale ressaltar que, para a anilha de efluentes os valores para a vazão não foram mensurados in situ, e sim calculados pela equação da vazão e considerou-se a população anual.

Santos et al.(2020), no estudo efetuado na Baia de Guajará, concluiram que o índice de poluição dos rios se eleva no período chuvoso que adentram o corpo hídrico via escoamento superficial. Já sul do Manaus - AM, Carvalho et al. (2014), verificaram que a vazão pode diminuir em função de obstáculos contidos no interior do rio, ou pelo estreitamento a que ele foi submetido e, com isso a carga poluitiva acumula-se prejudicando a qualidade da água. Em Ipixuna do Pará, no rio Ouricuri, a descarga de efluentes domésticos provoca uma grande quantidade de carga orgânica e depositam-se no rio, logo, não conseguem se dispersar pelo baixo nível de água, e isso é um considerável risco de degradação ambiental. Por isso, há a necessidade de estabelecer um controle rigoroso nos lançamentos de efluentes.

\subsubsection{Temperatura}

Os dados obtidos e analisados indicaram que, a temperatura no corpo hídrico apresentou tendência de equilíbrio, tanto no período chuvoso $\left(26^{\circ} \mathrm{C}\right)$, e no período seco no corpo hídrico $\left(25^{\circ} \mathrm{C}\right)$. Na anilha de efluentes, período chuvoso $\left(26,8^{\circ} \mathrm{C}\right)$, e período seco $\left(27,1^{\circ} \mathrm{C}\right)$ houve baixíssima variação térmica (Tabela 6).

Tabela 6. Valores (Máximo $=$ Vmáx.; Mínimo $=$ Vmín; média e desvio padrão $=\bar{x} \pm \sigma$ ) para a Temperatura $\left({ }^{\circ} \mathrm{C}\right.$ ) do Rio Ouricuri e da anilha de efluentes nos períodos chuvoso (P.C) e seco (P.S.). Capanema, Pará, Brasil.

\begin{tabular}{ccccccc} 
& \multicolumn{3}{c}{ Rio Ouricuri } & \multicolumn{3}{c}{ Anilha de efluentes } \\
\cline { 2 - 7 } & P.C & & P.S. & P.C & & P.S. \\
\hline \multirow{3}{*}{ Temperatura } & 26 & Tmáx. & 26 & 27 & Tmáx. & 27 \\
& 25 & Tmín. & 25 & 26 & Tmín. & 26 \\
& 24 & $\bar{x} \pm \sigma$ & 26 & 27 & $\bar{x} \pm \sigma$ & 27 \\
\hline
\end{tabular}

Fonte: Autores (2020).

O período chuvoso explicou a redução de $1^{\circ} \mathrm{C}$ na temperatura da água do rio Ouricuri $\left(\mathrm{de} 26^{\circ} \mathrm{C}\right.$ para $\left.25^{\circ} \mathrm{C}\right)$. Em relação a vazão, no período chuvoso equivaleu a $1,8 \mathrm{~m} \mathrm{~m}^{3} / \mathrm{s}$, já no período seco equivaleu a $0,93 \mathrm{~m}^{3} / \mathrm{s}$, com isso, a massa de água tende a armazenar uma quantidade menor de calor. Já na anilha, a explicação está relacionada a circulação do vento no interior desse tubo, logo, a tendência da temperatura é sofrer elevação. 
Acerca das variações de temperatura em rios, Antunes et al. (2) efetuaram estudo no rio Caeté, Bragança - PA, concluiram que a temperatura sofreu variações nos período seco $(29,8 \pm 0,2)$ e chuvoso $(30,3 \pm 03)$, já o OD, na mesma sequência $(\operatorname{seco}=3,7 \pm 0,9 ;$ chuvoso $=4,3 \pm 0,8)$, esse, sem grandes variações $\left(<1^{\circ} \mathrm{C}\right)$. Na pesquisa realizada por Carvalho et al. $(2013)$, no rio Ribeirão Novo, Araraquara - SP, os dados que eles obtiveram os permitiram escrever que a temperatura interfere nas taxas de reações químicas e na vida aquática. Em Ipixuna do Pará, as tendências de variações da temperatura ocorridas no rio Ouricuri, não mostraram tendências de variações significativas, logo, sem grandes influências nas concentrações do OD, que interferem na autodepuração do corpo hídrico.

\subsubsection{Coeficiente de desoxigenação $\left(k_{1}\right)$}

Para o Coeficiente de desoxigenação $\left(\mathrm{K}_{1}\right)$, não houve mensuração in situ. Os dados foram obtidos no software AD' ÁGUA 2.0 para os dois períodos analisados. Tais valores são exclusivamente relacionados com a anilha de efluente. Os parâmetros hidráulicos mensurados, além do coeficiente de reaeração $\left(\mathrm{K}_{2}\right)$, são necessários para simulação do processo de autodepuração (Tabela 7).

Tabela 7. Dados de entrada para o software AD’ÁGUA 2.0, em relação ao efluente e o curso d'água. Capanema, Pará, Brasil.

\begin{tabular}{|c|c|c|}
\hline & \multicolumn{2}{|l|}{ EFLUENTE } \\
\hline & Período chuvoso & Período Seco \\
\hline \multirow[t]{3}{*}{$\mathrm{K} 1\left(\mathrm{a}^{\circ} 6^{\circ} \mathrm{C}\right) / \mathrm{dia}^{-1}$} & 0,46 & 0,44 \\
\hline & \multicolumn{2}{|l|}{ CURSO D'ÁGUA } \\
\hline & Período chuvoso & Período Seco \\
\hline$V_{\text {média. }}(\mathbf{m} / \mathbf{s})$ & 0,79 & 0,56 \\
\hline $\mathbf{H}_{\text {média }}(\mathbf{m})$ & 17 & 17 \\
\hline $\mathbf{P}_{\text {média }}(\mathbf{m})$ & 0,33 & 0,33 \\
\hline $\mathbf{D}(\mathbf{k m})$ & $18 \mathrm{~km}$ & 18 \\
\hline $\mathrm{K}_{2} / \mathbf{d i a}^{-1}$ & 40,57 & 31,46 \\
\hline
\end{tabular}

Legendas: $\mathrm{V}_{\text {média.: }}$ Velocidade Média; $\mathrm{H}_{\text {média: }}$ altura médias $\mathrm{P}_{\text {média: }}$ profundidade média; D: distância. Fonte: Autores (2020).

$\mathrm{O}$ valor de referência para o coeficiente de desoxigenação $\left(\mathrm{K}_{1}\right)$, fornecido pelo software equivaleu 0,46 dia- ${ }^{1}$, no período chuvoso, e $0,44 \mathrm{dia}^{-1}$, no período seco. Isso em razão a temperatura do efluente, cujo valor médio foi igual a $26^{\circ} \mathrm{C}$ nos dois períodos. Esses valores permitiram a classificação da água como "Água residuária de baixa concentração", pois, os despejos dos efluentes no rio Ouricuri, tem origem nas residências e comércios existentes no trecho analisado. Por isso, esse corpo hídrico é considerado raso.

No rio Ribeirão Tatu, em Limeira - SP, foi realizada uma pesquisa sobre coeficiente de desoxigenação por Poletti e Cunha (2017). Os dados obtidos indicaram que, o corpo hídrico pôde ser caracterizado como "raso" isso em face dos efluentes domésticos sem tratamento que são despejados nesse Ribeirão. Com esse despejo, e por tratar-se de um rio urbano, ele tornouse um manancial de velocidade intermediária por ter perdido as características lóticas. O rio Ouricuri também é um rio urbano e recebe descarga orgânica, que resulta na perda dos fluxos de água e também nas características lóticas, com isso, os dados obtidos em Capanema, são similares aos descritos para o Ribeirão Tatu.

\subsubsection{Velocidade do curso d'água}


No curso d'água, a velocidade média mensurada in situ, no curso d'água foi e $0,79 \mathrm{~m} / \mathrm{s}$, período chuvoso, sendo superior ao período seco $(0,56 \mathrm{~m} / \mathrm{s})$. No trecho analisado foi obtido a altitude média $(17 \mathrm{~m})$ em razão das coordenadas geográficas dos pontos de coleta de dados no rio Ouricuri. O valor da profundidade média do trecho estudado, nos períodos sazonais analisados, ela foi igual $0,33 \mathrm{~m} / \mathrm{s}$.

Nos estudos efetuados por Bárbara et al. (2009) no rio Araguari - AP, os autores concluiram que, as características do corpo hídrico podem ser avaliadas a partir dos valores médios para a velocidade, altitude e profundidade. Em relação ao Rio Ouricuri, os dados das variáveis indicaram que ocorreu a modificação da paisagem, a capacidade de erosão e as perdas das características naturais.

\subsubsection{Coeficiente de reaeração $\left(K_{2}\right)$}

Para a simulação da capacidade de autodepuração, os dados obtidos no software AD' ÁGUA para o valor de Coeficiente de Reaeração $\left(\mathrm{K}_{2}\right)$ equivaleu $40,57^{-1}$, no período chuvoso, e $31,46^{-1}$, no período seco. Esses valores estão em função da profundidade e da velocidade que evidenciou a diminuição na oxigenação do recurso hídrico e, permitiram a classificação do rio Ouricuri como "vagaroso". Com isso, a absorção do oxigênio atmosférico pela água não está sendo efetiva a partir do escoamento. Sobre os valores para o oxigênio dissolvido e a reposição dele, Gorayeb et al.(2007), efetuou estudo sobre essa variável limnológica no rio Curi, em Santa Luzia do Pará - PA, nos períodos chuvosos e seco, as concentrações do OD estavam acima do estipulado pela Resolução CONAMA 357 (2005). Em Santa Izabel do Pará - PA, Morais (2012), realizou pesquisas no igarapé Santa Izabel - PA, e os valores para $\mathrm{K}_{2}$ encontrados indicam que a variação da temperatura da água influencia na absorção atmosférica do oxigênio. No rio Ouricuri, houve a interferência de uma terceira variável: a temperatura para que o valor de $\mathrm{K}_{2}$ fosse baixo.

\subsection{Simulação da capacidade de autodepuração}

\subsubsection{Período chuvoso}

A análise dos dados obtidos indicou que a concentração de OD no período chuvoso, atingiu o máximo permitido (> m mg/L) pela Resolução CONAMA 357 (2005) em relação a duas variáveis: distância, em km (Figura 6A), e o tempo em dias (Figura 6B) de forma bastante expressiva.

Figura 6. Concentração do oxigênio dissolvido em função da distância e do tempo no período chuvoso, Rio Ouricuri, Capanema, Pará, Brasil.

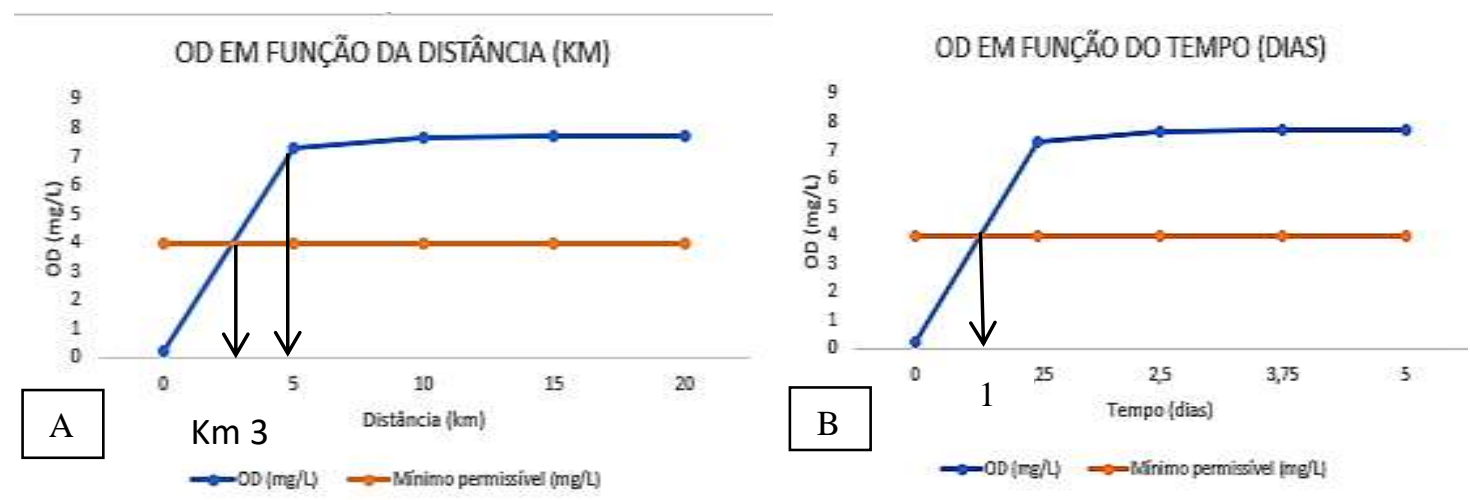

Fonte: Autores (2020). 
$\mathrm{Na}$ análise da concentração do OD em função da distância, verificou-se que o decaimento máximo ocorre no ponto de lançamento de efluentes ( $\mathrm{Km}$ 3), a concentração atinge o limite estabelecido (4 mg/L) pela Resolução CONAMA n. 357 (2005). Em função do tempo, um dia, o valor estabilizou e se mostrou conformidade com essa resolução. Já Km5, a concentração se eleva para $7 \mathrm{mg} / \mathrm{L}$, e no Km 10, atinge $8 \mathrm{mg} / \mathrm{L}$ Isso até o final do primeiro dia.

Na revisão de literatura efetuada por Andrade (2010), sobre capacidade de autodepuração, concluiu que os estágios de sucessão ecológica presentes no processo da autodepuração de um curso d'água são identificados por trechos: zonas de águas limpas, zona de degradação, zona de decomposição ativa e zona de recuperação.

Na simulação do trabalho atual, a análise dos dados obtidos indicou que a montante do ponto de lançamento, antes do km 0, é considerada a zona de águas limpas, A zona de degradação corresponde ao ponto de lançamento do efluente doméstico, onde inicia o processo de decaimento do oxigênio dissolvido, neste caso no km 0 . A zona de decomposição ativa, onde acontece maiores interferências de microrganismos na decomposição da matéria orgânica e maior consumo do oxigênio dissolvido presente na água, é o trecho compreendido entre o $\mathrm{km} 0$ e o km 5 . A zona de recuperação começa a partir do $\mathrm{km} 5$ à jusante, até o curso d'água elevar o nível máximo de OD, chegando, novamente, à zona de águas limpas.

Moruzzi et al. (2012), efetuou estudo no Córrego Asa Branca, Itapira - SP, e concluiu que, em muitos casos, a distância necessária para a autodepuração é maior que a distância física do rio. O rio Ouricuri necessita de $5 \mathrm{~km}$ após o lançamento de efluentes para elevação do oxigênio dissolvido que atinge em um dia, Se não houver mais despejos de efluentes domésticos no decorrer de seu trecho, por se tratar de um rio de pequena extensão, que perpassa pela zona urbana e deságua na zona rural, deve percorrer esse trajeto para autodepurar. Isso se houver formulação dos pontos de despejos dos efluentes domésticos, a uma distância mínima de 5km, para que o corpo hídrico equilibre os índices de OD.

\subsubsection{Período seco}

Para esse período, os dados analisados indicaram que a concentração do OD, foi mais elevada no $\mathrm{Km} 3$, quando relacionado à distância, em km (Figura 7A) e ao tempo em dias (Figura 7B). O trecho onde isso ocorreu houve a ocorrência do lançamento de efluentes domésticos no trecho analisado.

Figura 7. Concentração do oxigênio dissolvido em função da distância e do tempo, período seco. Rio Ouricuri, Capanema, Pará, Brasil.
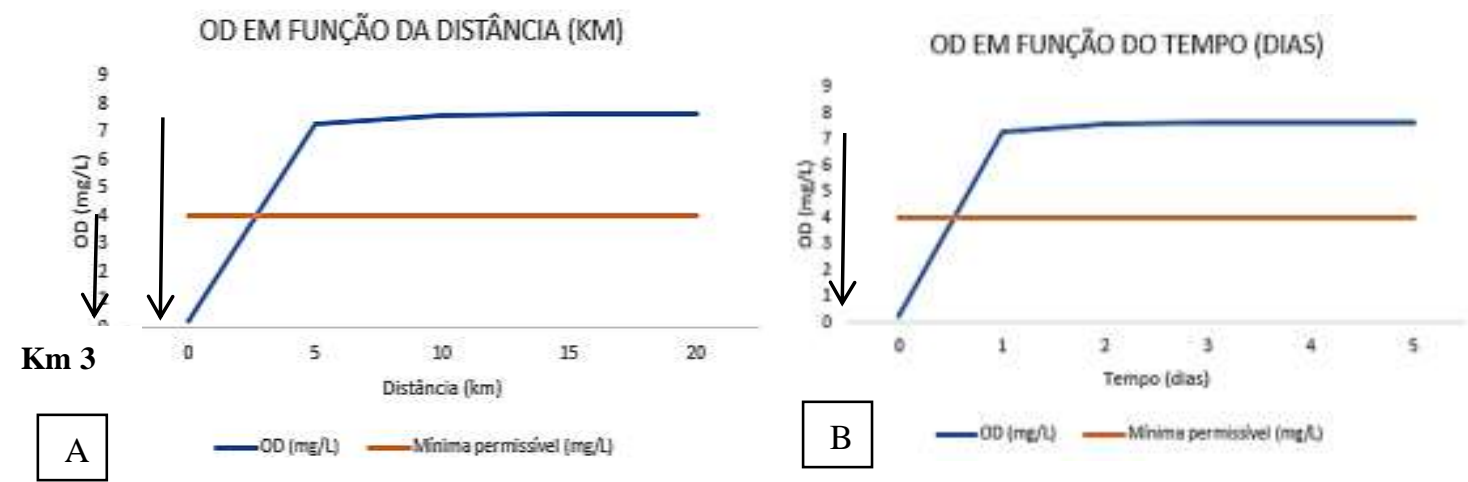

Fonte: Autores (2020).

$\mathrm{Na}$ análise da concentração do OD em função da distância, verificou-se que o decaimento máximo ocorreu no ponto de lançamento de efluentes, o OD se estabelece no do corpo hídrico, atinge o nível mínimo permitido pela legislação (4 mg/L) 
no Km3. Em função do tempo, o OD fica em conformidade com a legislação no período equivalente a menos de um dia. Em mais de um dia, ou seja, no quinto, atingiu o nível superior a $7 \mathrm{mg} / \mathrm{L}$ no $\mathrm{km} 5$ e se torna constante a partir do $\mathrm{km} 15$ com quase quatro dias.

Guedes (2009), no rio Pomba, Viçosa - MG, realizaram uma pesquisa sobre a capacidade de autodepuração em relação ao perfil de oxigênio dissolvido no período chuvoso e seco, avaliou que no período seco há menor concentração de OD no corpo hídrico, o que dificulta a assimilação das cargas orgânicas depositadas nos rios, diminuindo a capacidade de autodepuração durante esse período. No rio Ouricuri, a simulação de autodepuração apresentou a mesma tendência, ou seja, atingiu o valor de OD atingiu o mínimo permissível pela legislação no km 3, elevando os níveis a partir do km 3. Obteve as mesmas zonas de autodepuração nos dois períodos analisados.

As zonas de autodepuração, para o estudo realizado durante o período seco, tem-se zona de águas limpas: antes do km 0; zona de degradação: no km 0 (ponto de lançamento do efluente); zona de decomposição ativa: trecho entre o 0 a $5 \mathrm{~km}$ (ponto onde ocorreria a maior taxa de decaimento do oxigênio dissolvido presente no corpo hídrico); Zona de recuperação: se iniciaria logo após o km 5, com o aumento contínuo da quantidade de oxigênio dissolvido no corpo d'água até retornar as características próximas das anteriores ao lançamento.

\section{Recomendações}

O Rio Ouricuri tem condições para autodepurar, mas, para isso é necessário a adoção de medidas mitigatórias quanto a cargas orgânicas, oriundas das anilhas de efluentes domésticos lançado no rio. Por isso, sugere-se:

- Tratamento dos efluentes domésticos, antes do lançamento no corpo hídrico, para diminuir a concentração de DBO da matéria orgânica disposta no rio, o método de tratamento de esgotos domésticos devem ser comparados e organizados em três critérios: 1) definição (aeróbio, anaeróbio e outros), 2) operação (física, química, biológica e outras) e 3) por nível (prétratamento, primário, secundário e terciário). Uma outra alternativa são as fossas sépticas biodigestoras elaboradas pela EMBRAPA.

- Formulação de pontos de despejos dos efluentes, para que o rio não receba durante todo o seu percurso efluentes, assim, não conseguindo alcançar a distância necessária para a elevação dos níveis de OD, consequentemente não autodepurar. Deve- se estruturar pontos específicos em uma distância determinada de um ponto pro outro, considerando e extensão do corpo hídrico.

- Incrementar nas escolas de ensino fundamental ( $6^{\circ}$ ao $9^{\circ}$ ano) e no ensino médio, no caso de Capanema, a Educação Ambiental Crítica, para que haja transformação social e incremento as sensibilidade quanto a uso e conservação dos recursos naturais, dentre eles, os rios, para cumprir o descrito no artigo 225, inciso VI da Constituição Federal, e elevar o número de agenciadores da conservação ambiental.

\section{Conclusão}

A capacidade de autodepuração do Rio Ouricuri, depende de medidas mitigatórias, como tratamento prévio do esgoto doméstico para diminuição da carga orgânica disposta no rio e formulação de pontos de despejos desses efluentes. O corpo hídrico está em estado crítico, com baixos níveis de oxigênio dissolvido para rios de classe III e, consequentemente interfere diretamente na vida aquática, por isso, é de grande importância o planejamento e execução de tratamento prévio do esgoto doméstico para diminuição da carga orgânica disposta no rio. Por meio deste estudo, foi possível simular cenário para as condições de autodepuração do Rio Ouricuri, após o despejo de efluentes líquidos provenientes da população do município de Capanema - PA. 
Atualmente as águas do Rio Ouricuri são consideradas poluídas, e a quantidade de oxigênio dissolvido tem valor abaixo das quantidade permitida por lei para corpos de água doce de classe 3. No entanto, na área analisada para a simulação de autodepuração a partir dos despejos lançados, o rio teria condições para se auto depurar se não houvesse outra carga de lançamento de até $5 \mathrm{~km}$. Nesse caso, seria necessário a implantação de pontos específicos para a anilha de efluentes, por isso importância em conhecer a capacidade de assimilação do rio.

Porém, ainda não há tratamento de esgoto domésticos em funcionamento no município, os resultados obtidos no trabalho devem estimular a prática das medidas para recuperação do rio, bastando apenas relacionar valores de cálculos e proporcioná-los em conformidade com a situação real dos efluentes lançados no corpo d’água.

As estimativas realizadas no estudo demonstraram consequências negativas alarmantes que já são possíveis de avaliar visualmente durante o trecho estudado no rio. Ou seja, se o corpo hídrico recebesse valores de saídas domésticas tratados e com pontos específicos, segundo este estaria sujeito a alterações do seu ecossistema, pois nas suas condições atuais está prejudicando toda uma cadeia que necessita, de alguma forma, dos recursos oferecidos pelo rio.

Em síntese, o estado ambiental da água do rio Ouricuri, atualmente, é imprópria para captação, abastecimento, em função do pH, e balneabilidade, devido as alterações de OD e DBO, devido ao grau de poluição que se encontra.

\section{Referências}

Andrade, L. N. (2010). Autodepuração dos corpos d'água. Revista da Biologia, 59, 16-19. https://www.revistas.usp.br/revbiologia/article/view/108617 /106924. http://dx.doi.or/10.7594/revbio.05.04

Alvarenga, L. A.; Martins, M. P. P.; Cuartas, L. A.; Penteado, V. A., \& Andrade, A. (2012). Estudo da qualidade e quantidade da água em microbacia, afluente do rio Paraíba do Sul - São Paulo, após ações de preservação ambiental. Ambi-Agua, 7(3), 228-240. https://www.scielo.br/pdf/ambiagua/v7n3/v7n3a18.pdf. http://dx.doi.org/10.4136/1980-993X

Antunes, L. C., Santos, M. L. S., Batista, R. M. M., Alves, I. C. C., \& Palheta, G. D. A. (2013) Influência da maré nas condições ambientais na orla do município de Bragança, norte do estado do Pará. Boletim Técnico Científico do CEPNOR, 13(1), 23-31. file:///D:/Downloads/1437-7012-1-PB\%20(1).pdf. http://dx.doi.org/10.17080/1676-5664/btcc.v13n1p23-31

Arcos, A. N., Silva, J. S., \& Cunha, H. B. (2020). Grupo coliforme fecal como indicador de balneabilidade em praia de água doce no Rio Negro, Amazonas. Research, Society and Development, 9(7), e238974015. https://rsdjournal.org/index.php/rsd/article/view/4015/3398. http://dx.doi.org/10.33448/rsd-v9i7.4015

Bárbara, V. F., Siqueira, E. Q., \& Cunha, A. C. (2009). Estimativa do coeficiente de reaeração (K2) para o Rio Araguari-AP (Amazônia) para posterior utilização no modelo de qualidade da água QUAL2E. https://www.bionorte.org.br/bionorte/ppg-numeros-producao.html?idp=41019

Batista, F. D., \& Cabral, J. B. P. (2017). Modelos matemáticos para avaliação do índice de qualidade de água. ACTA Geográfica, . 11(25), 111-136. https://revista.ufrr.br/actageo/article/view/4021. http://dx.doi.org/10.5654/acta.v11i25.4021

Bezerra, J. C. F., Dias, J. G. S., Oliveira, A. T. S., Ribeiro, A. T. \& Daniel R. (2017). Medição de vazão em um canal fluvial utilizando oo método do flutuador. Anais do Congresso Internacional das Ciências Agrárias, 2, Natal, Brasil. https://cointer-pdvagro.com.br/wp-content/uploads/2018/02/MEDIÇÃODE-VAZÃO-EM-UM-CANAL-FLUVIAL-UTILIZANDO-O-MÉTODO-DO-FLUTUADOR-086191-1.pdf. http://doi.org/10.31692/2526-7701.IICONIN TERPDVAGRO.2019.00374

Carvalho, E. M.; Bentos, A. B.; \& Pereira, N. S. (2013). Avaliação rápida da diversidade de habitats em um ambiente lótico. Revista Ibero-Americana de Ciências Ambientais, 5(1),129-139. https://sustenere.co/index.php/rica/article/view/SPC2179-6858.2014.001.0009/394. http://dx.doi.org/10.6008/SPC21796858.2014.001.0009

Carvalho, R., Tartatir, R., Radmann, V., \& Pagani. C. H. P. (2014). Monitoramento da vazão em rios da região sul do Amazonas. Revists EDUAmânia educação, Sociedade e Meio AMBIENT, 12(1), 08-27. Recuperado de: file:///D:/Downloads/Dialnet-MonitoramentoDaVazaoEmRiosDaRegia oSulDoAmazonas-4730897.pdf.

Cordeiro, J., Silva, F. H., Campera, F. A. N., \& Costa, F. (2020) Sistema de drenagem urbana e o saneamento: uma análise cien ciométrica. Research, Society and Development, 9(11), e12391119616. https://rsdjournal.org/index.php/rsd/article/view/9616. http://10.33448/rsd-v911.9616

Costa, J. S., Oliveira, A. N., Souza, F. P., \& Macedo, W. J. C. (2016). Ocupação da app do rio Ouric uri por feira municipal de Capanema, Pará: uma análise socioeconômica e ambiental. In: Anais do Congresso Amazônico De Meio Ambiente \& Energias Renováveis, 2, Belém, Pará, Brasil. https://www.even3.com.br/anais/camaer2016/30913-ocupacao-da-app-do-rio-ouricuri-por-feira-municipal-de-capanema-para--uma-analise-socioeconomica-eambiental/\#: :text=OCUPAÇÃO\%20DA\%20APP\%20DO\%20RIO,UMA\%20ANÁLISE\%20SOCIOECONÔMICA\%20E\%20AMBIENTAL\&text=O\%20des envolvimento $\% 20$ acelerado $\% 20 \mathrm{e} \% 20$ desorganizado,Permanente $\% 20(\mathrm{APP}) \% 20 \mathrm{de} \% 20$ rios.

Gorayeb, A., Guimarães, S. T. L., Pereira, L. C. C., \& Guimarães, D. O. (2007). Analise da qualidade da água na bacia hidrográfica do Caeté (Pará, Brasil). Recuperado de: http://www.abequa.org.br/trabalhos/2007_adryane_gorayeb_gerenciamento.pdf 
IBGE. Capanema, Pará, 2017. https://cidades.ibge.gov.br/brasil/pa/capanema/panorama>.

Jouanneau, S., Recoules, L., Durand, M. J., Boukabache, A., Picot, V., Primault, Y., Lakel, A.. Sengelin, M. Barillon, B., \& Thouand, G.et al. (2014). Methods for assessing biochemical oxygen demand (BOD): A review. Water research, 49, 62-82. https://www.sciencedirect.com/science/article/abs/pii/S 0043135413008920. doi:http://dx.doi.org/10.1016/j.watres.201310.066

Lima, L. D. B. (2015). Dos trilhos às rodas: histórias e memórias de Capanema. Paka-Tatu

Matias-Pereira, J. (2016). Manual de metodologia de pesquisa cientifica. (4a ed). Atlas.

MICROSOFT CORPORATION (2016). Excel. Version 2016, https://www.microsoft.com/pt-br/download/details.aspx?id=55017

Miranda, R. F., Ribeiro, A. C., \& Aquino, D.S. (2016) Modelagem matemática ambiental: desenvolvimento de aplicativo Android para estimativa de autodepuração de cursos d'água. Anais do Simpósio Brasileiro de Engenharia Ambiental, 14, https://tratamentodeagua.com.br/artigo/modelagem-matematicaambiental-desenvolvimento-de-aplicativo-android-para-estimativa-da-autodepuracao-de-cursos-dagua/

Morais, K. M. C. (2012). Autodepuração do igarapé Santa Isabel no município homônimo - aplicação do modelo de Streeter-Phelps. (Dissertação de Mestrado). Universidade Federal do Pará. http://repositorio.ufpa.br/jspui/bitstream/2011/6269/1/Dissertacao_AutodepuracaoIgarapeSanta.pdf

Moruzzi, R. B., Conceição, F. T., Sardinha, S. S., Honda, F. P., \& Navarro, G. F. B. (2012). Et Al. Avaliação de cargas difusas e simulação de autodepuração no córrego da Água Branca, Itirapina (SP). Geociências, 31(3), 447-458. http://www.revistageociencias.com.br/geocienciasarquivos/31_3/Art_10_Moruzzi_et_al.pdf

Pereira, A., Shitsuka, D. M., Parreira, F. J., \& Shitsuka, R. (2018). Metodologia da Pesquisa Científica. UFSM.

Oliveira, T. M. B. F., Souza, L., \& Castro, S. S. L. (2018). Dinâmica da série nitrogenada nas águas da bacia hidrográfica Apodi/Mossoró-RN-Brasil. Eclética Química Journal, 34(3),17-26. https://www.scielo.br/pdf/eq/v34n3/02.pdf. http://dx.doi.or/10.1590/S0100-46702009

Palhares, P. C J., Ramos, J. C. P., Klein, J. B., Lima, J. C. M. M., Muller, S., \& Cestonaro, T. (2007). Medição de vazão em rios pelo método flutuador. Concórdia: EMBRAPA.

Pará. (2016). Estatísticas Municipais Paraenses: Capanema. FAPESPA.

Poletti, E. C. C., \& Cunha, A. C. (2017). O Processo de Autodepuração do Ribeirão Tatu: Modelagem e Simulações. Proceeding series of the Brazilian Society of Computational and Applied Mathematics, 5(1), 1-6. https://proceedings.sbmac.org.br/sbmac/article/view/1237/0. http://doi.or/10.5540/03.201 7.005.01.0069

Queiroz, M. F. M., Matos, A. T., \& von Sperling, M. (2015). Estimativa do coeficiente de reaeração da água em canal raso de fundo deslizante. Engenharia Sanitária e Ambient, 20(1),79-88. https://www.scielo.br/pdf/esa/v20n1/1413-4152-esa-20-01-00079.pdf http://doi.org/10.1590/S1413-4152015020000113819

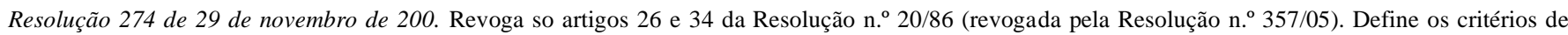
balneabilidade em águas brasileiras. Recuperado de: http://www2.mma.gov.br/port/conama/legiabre.cfm?codlegi=272

Resolução 357 de 17 de março de 2005. Dispõe sobre a classificação dos corpos de água e diretrizes ambientais para o seu enquadramento, bem como estabelece as condições e padrões de lançamento de efluentes, e dá outras providências. http://pnqa.ana.gov.br/publicacao/resolucao_conama_n_357.pdf.

Resolução 430 de 13 de maio de 2011. Dispõe sobre as condições e padrões de lançamento de efluentes, complementa e altera a Resolução n. ${ }^{\circ} 357$, de 17 de março de 2005, do Conselho Nacional do Meio Ambiente. http://www.labb.com.br/wp-content/pdf/Resolucao_CONAMA_430_11.pdf

Sales, M. J. R. (2014). Aplicação da lógica Fuzzy no modelo de Streeter-Phelps para analisar o risco de contaminação das águas de rios, considerando múltiplos processos e múltiplos lançamentos. (Tese de Doutorado). Universidade Federal do Ceará, Fortaleza, CE, Brasil. http://www.repositorio.ufc.br/handle/riufc/11578

Santiago, D. R., Matos, K. C., Lopes, W. G. R., Falcão, A. L. S., \& Sampaio, I. M. R. (2020). Convivência da cidade com seus rios: estudo da paisagem ribeirinha em Teresina, Piauí, Brasil. Research, Society and Development, 9(11), e1209119582. https://rsdjournal.org/index.php/rsd/article/view/9582 http://dx.doi.org/10.33448/rsd-v911.9582

Santos, L. F., Marinho, E, R., \& Moreira, F. S. A. (2020). Avaliação da qualidade da água da baia de Guajará em Bel,/PA. Revista Ibero-americana de

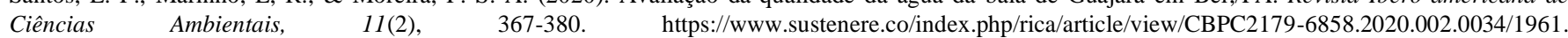
http://dx.doi.org/10.6008/CBPC2179-6858.2020.002.0034

Santos, R. A., Saito, N. S., Peluzio, T. M. O., \& Braga, J. C. (2010). AD’ÁGUA 2.0: Sistema para simulação da autodepuração de cursos d'água - Manual do Usuário. Alegre, ES: CAUFES.

Santos, L. B. D. (2018). Rios urbanos brasileiros, um bem comum poluído. Escenarios: empresa y território, 7(9), 9-12. https://revistas.esumer.edu.co/index.php/escenarios/article/view/12. http://dx.doi.org/10.31469/escenarios

Silva, K. W. S., Everton, N. S., \& Melo, M. A. D. (2016). Aplicação dos índices biológicos Biological Monitoring Working Party e Average Score per Taxon para avaliar a qualidade de água do rio Ouricuri no Município de Capanema, Estado do Pará, Brasil. Revista Pan-Amazônica de Saúde, 7(3), 13-22. http://dx.doi.org/10.5123/52176-62232016000300002

Silva, L. M. (2012). Estudo da correlação entre o oxigênio dissolvido e a matéria orgânica em diferentes ambientes aquáticos da região Amazônica. (Dissertação de Mestrado). $\quad$ Universidade Amaleral al Amazonas. https://tede.ufam.edu.br/bitstream/tede/3341/4/Luana\%20Monteiro\%20da\%20Silva.pdf

Siqueira, R. M. B.; Henry-Silva, G. G. (2011). A bacia hidrográfica como unidade de estudo e o funcionamento dos ecossistemas fluviais. Boletim da Associação Brasileira de Limnologia, 39(2), 1-15. Recuperado a partir de https://www.ablimno.org.br/boletins/pdf/bol_39(2-6).pdf 
Research, Society and Development, v. 10, n. 5, e19110514890, 2021

(CC BY 4.0) | ISSN 2525-3409 | DOI: http://dx.doi.org/10.33448/rsd-v10i5.14890

Streeter, H. W., \& Phelps E. B. (1925). A Study of the Pollution and Natural Purification of the Ohio River, Washington, D. C.: U.S. Department of Health, Education, \& Welfare. https://udspace.udel.edu/bitstream/handle/19716/1590/C\%26EE148.pdf?sequence=2\&isAllowed=y

Uieda, V. S. (2011). A obra literária: ecologia de ambientes lóticos. (Tese de doutorado). Universidade Estadual Paulista "Júlio de Mesquita Filho". São Paulo, SP, Brasil. https://repositorio.unesp.br/handle/11449/106725

Valente, J. P. S., Padilha, P. M., \& Silva, A. M. M. Oxigênio dissolvido (OD), demanda bioquímica de oxigênio (DBO) e demanda química de oxigênio (DQO) como parâmetros de poluição no ribeirão Lava-pés/Botucatu - SP. Eclética Química, 22, 49-66. http://www.scielo.br/scielo.php?script=s ci_arttext\&pid=S0100-46701997000100005\&lng=en\&nrm=iso http://dx.doi.org/10.1590/S0100-46701997000100005

Vargas, E. H.; \& Marques, F. S. (2015). Análise da Autodepuração do Curso D’água Pomba Cuê Utilizando o Modelo Streeter Phelps. Revista Pleiade, 9(17), 83-92. https://pleiade.uniamerica.br/index.php/pleiade/article/view/283/468

Vasconcellos, K. C., Araújo, F. A. J., \& Sales, M. J. (2014). Risco de falha ambiental em um rio sujeito à concessão de outorga de lançamento de efluentes, mediante aplicação da equação de Streeter-Phelps na lógica fuzzicada. https://amigosdanatureza.org.br/publicacoes/index.ph p/forum_ambiental/article/view/872. Fórum Ambiental da Alta Paulista, 10(2),199-214. https://amigosdanatureza.org.br/publicacoes/index.php /forum_ambiental/article/view/872. http://dx.doi.org/10.17271/1980082710202112872

Vieira, A. S. A., Crispim, D. L., Rodrigues, R. S. S., Silva, I. Q., \& Pessoa, F. C. L. (2018). Resposta hidrológica às mudanças climáticas em Capanema - PA - um município da Amazônia. Revista GEONORTE, 9(32),67-79. file:///D:/Downloads/3559-Texto\%20do\%20artigo-12658-1-10-20180629\%20(2).pdf. http://dx.doi.org/10.21170/geonorte.2018.V .9.N.32.67.79

Viveiros, J. I. A. (2009) Capacidade de autorrecuperação de cursos d'água urbanos: estudo de caso: Córrego Campestre em Lins - SP. Universidade Estadual Paulista. Mestrado em Engenharia Civil. https://repositorio.unesp.br/bitstream/handle/11449/98056/viveiros_jia_me_ilha.pdf?sequence=1\&isAllowed=y

Von Sperling, M. (2005). Princípios básicos do tratamento de esgotos. (3a ed.), UFMG.

Von Sperling, M. (2009). Introdução a qualidade das águas e ao tratamento de esgotos. (2a ed.). UFMG.

Von Sperling, M. (2011). Introdução à qualidade das águas e ao tratamento de esgotos (4 ed.). https://www.livrostecnicos.com.br/agua/qualidade-aguatratamento-esgoto-von-sperling 